\title{
Research on the Current Situation of Chinese Large Stadium Financing and Its Countermeasures
}

\author{
Honghai Li \\ College of Physical Education \\ Northwest Normal University \\ Lanzhou, China 730070
}

\begin{abstract}
The financing problem of large stadiums is an urgent problem to be solved. Through literature research, interviews, analysis and comparison and other methods, and in combination with the reality of economic and social development, this research analyzes and summarizes the current financing status of Chinese large-scale stadiums and its causes, and systematically organizes the financing modes and methods of different types of large stadiums, and finally proposed countermeasures.
\end{abstract}

Keywords-large stadiums; financing; status quo; countermeasures

\section{INTRODUCTION}

With the development of the sports industry, the shortage of funds has become increasingly prominent, and the financing of the sports industry has begun to come to people's field of vision and has received attention. Among them, the construction of large-scale sports stadiums, because of the characteristics of large investment, high operating costs and long investment recovery period, caused huge financial pressure on the country, but the relevant sports demand could not be better met. Through literature research, expert interviews and comparative analysis, this study summarizes the current situation of Chinese large-scale sports stadium financing under current economic and social background and its causes, analyzes the optional financing modes of large stadiums, and finally gives corresponding countermeasures, which has a certain practical guiding significance.

\section{ANALYSis OF THE STATUS QUO OF CHINESE LARGE- SCALE SPORTS STADIUM FINANCING AND ITS CAUSES}

\section{A. Status Quo of Chinese Large-scale Stadiums Financing}

From the different research scopes, research objects and research contents, the theoretical circles have used different research methods to study the financing of large stadiums. By comprehensive analysis of relevant literature, it is found that the current financing of large stadiums in China presents the following characteristics. (1) huge funds demand for construction of stadiums, but seriously insufficient supply and investment; (2) relatively single investment entities, dominated by government departments at all levels; (3) narrow financing channels, single financing methods, and dominated by government financial funds; (4) low marketization of stadium facilities financing, and relatively low investment efficiency; (5) high operation and maintenance costs of large-scale sports stadiums, but seriously insufficient investment; (6) Since the establishment of the socialist market economic system, the investment entities of large-scale sports stadiums are diversified. [1] [2] [3] [4]

\section{B. Cause Analysis}

1) Properties of large stadiums: According to economic theory, most stadiums are quasi-public products. In China, various sports stadiums are the necessary facilities to meet the needs of mass fitness and entertainment, sports competitions and professional training of sports teams, and they also the material basis and guarantee for the development of the sports industry. At the same time, the construction of large-scale sports stadiums requires huge funds, and individuals and enterprises are generally unbearable, so the governmental financial funds allocation often becomes a major and single source of funding. In addition, the consumption of stadiums is often noncompetitive, and each additional consumer does not affect the consumption of other consumers, so stadium facilities must be supplied free of charge if they are priced according to marginal cost. In this way, market entities are often reluctant to invest in the construction of sports stadiums [1].

2) Impact of traditional investment and financing systems: Since the reform and opening up, the traditional investment and financing system has made new breakthroughs of reform, but it is still at a relatively lagging stage. The investment and financing system of stadium facilities based on governmental investment has made active and powerful contributions to the rapid development of large-scale sports facilities in China in a specific historical period, but it is difficult to adapt to the rapid growth of market economy and the growth of demand for stadium facilities. At present, due to the existence of institutional inertia, it still profoundly affects the investment and financing practices of large stadiums in all aspects, which restricts the development of large-scale sports facilities in China to a certain extent. Through questionnaire survey, 
some scholars believe that the shortcomings of the investment and financing system are the main reasons of single investment entities and fund source of current largescale stadium facilities in China and of low investment efficiency. Because of the long-term influence of the traditional investment and financing system of stadium facilities, the governmental departments still have a relatively low awareness of investment and financing in stadium facilities. They believe that the governmental department is the only supplier of stadium facilities and fail to recognize the provision and the production of stadium facilities are two different and separable processes [1].

3) Unsound recovery mechanism of investment and financing: Capital is profit-seeking, and investment tends to the profitable industry. Whether the stadium facilities have a good investment return mechanism and a good return rate is an important factor affecting private capital investment. Wang Jian and Chen Yuanxin (2006) believe that the reason why the construction of stadium facilities in foreign developed countries of market economy can attract private capital investment lies in its sound and stable investment return mechanism of stadiums [5]. The poor operating conditions and low profitability of most sports stadiums are a common problem in China.

\section{ANALYSIS OF OPTIONAL FINANCING MODES FOR LARGE STADIUMS}

Xiao Shuhong and Fu Qun (2012) divided the financing modes of large-scale stadiums into three categories according to their sources of funds: governmental capital investment; social capital investment; public-private joint capital investment [6,7]. This category method basically covers all the financing methods of large stadiums at home and abroad.

\section{A. Financing Mode of Governmental Capital Investment}

This mode has absolute control over the stadium, which is convenient for the government to control comprehensively from macro to micro, and the mode is easy to operate. However, this mode will increase the government's financial burden, and because it does not introduce market competition mechanism, it is also not conducive to mobilizing social capital for active participation in the investment and construction of sports stadiums. The mode has the following methods: governmental fiscal investment mode, financial subsidy plus self-raising mode, sports lottery public welfare fund mode, tax distribution system mode [6].

\section{B. Financing Mode of Social Capital Investment}

The social capital investment relies on the market to raise funds for the construction of large-scale sports stadiums. It is conducive to alleviating the national burden of fund in stadium construction and the insufficiency of national financial allocations, and it is conducive to solving the shortage of large-scale sports stadiums in China and the imbalance of stadiums layout and structure and so on. However, in the operation of this mode, due to lack of control and management rights of the government, it may have a certain degree of impact on the development of sports in the whole society. At present, this mode mainly has the following methods: commercial development operation mode, stock financing mode, bond financing mode, lease financing mode, social donation plus self-raising mode, bank loan financing mode, intangible asset financing mode, and venture capital financing mode and $\mathrm{ABS}$ financing mode introduced[6].

\section{Financing Mode of Public-private Joint Capital Investment}

This is a cooperative mode, carried out through a set of agreements where the two parties share investment risks, responsibilities and investment returns. It relieves the government's financial burden to a certain extent, and while increasing the enthusiasm of social capital to participate in the financing construction of large-scale sports stadiums, it makes the public welfare goal of sports guaranteed. The mode mainly include the methods: PPP mode, BOT mode, TOT mode, PFI mode, provincial school cooperation mode, LCP mode, land replacement financing mode, compensation input mode, profitable project and sports facility bundling operation mode, commercial development and operation financing mode [6].

\section{FINANCING COUNTERMEASURES FOR LARGE STADIUMS IN CHINA}

The practice of building large-scale sports stadiums at home and abroad shows that it is the best choice to establish a government-led, market-oriented, diversified financing mode of large-scale stadiums. The coexistence of multiple financing modes (methods) will effectively solve the dilemma of large investment costs, high operating costs and low investment efficiency of large stadiums. At the same time, for the choice of financing mode (method), we must consider the following factors: the characteristics of large stadiums, the characteristics of various financing modes, and the plans and goals of economic and social development. China is a country of socialist market economy and it always puts the interests of the people first. The relationship between the public welfare and the management of sports stadiums must be treated correctly with enough attention.

\section{A. Actively Changing the Role of Government}

Since the founding of New China, large-scale sports stadiums have experienced rapid growth, and the strong promotion of government departments at all levels is indispensable. However, under the new normal of economic and social transformation, it is far from a good thing for too much governmental control, or it will limit the role of the market, so the government needs to make its contribution to institutional innovation, changes and maintenance of the operation environment, and market regulation. 


\section{B. Deepening the Reform of Investment and Financing System for Large Stadiums}

In 2016, "Opinions of the Central Committee of the Communist Party of China and the State Council on Deepening the Reform of Investment and Financing System" clarified the top-level design of investment and financing system reform in various industries, which gives a strong institutional guarantee for deepening the reform of investment and financing system for large-scale sports stadiums, and improving the diversified investment and financing mechanisms of large-scale sports stadium, and playing roles of various investment and financing to the growth of the number of large stadiums and the optimization of the structure. In the future, the status of enterprises as investment entities will be further improved, enterprises will have more autonomy in investing in various large-scale sports stadiums, and their enthusiasm for investing social capital in large-scale sports stadiums will be greatly enhanced.

\section{Choosing a Reasonable Financing Method}

In addition to making full use of the financial fund allocations of government departments at all levels and the bank loan, about the fund financing methods for the construction of large-scale sports stadiums we also should actively explore and learn from new financing methods and experiences. From a global perspective, the application of BOT, TOT, PFI, PPP and other modes have been mature in many industries or fields, especially the PPP mode is favored by all countries, especially the developing countries due to its financing mode of governments, enterprises and individuals sharing risks and benefits.

\section{Cultivating High-quality Comprehensive Professional Management Talents}

High-quality comprehensive management talents with knowledge integration and technology integration are important guarantees for the smooth implementation of project management. Various new financing methods, such as BOT, TOT, PFI, PPP, etc., involve the knowledge or ability of negotiation skills, contract signing, risk management, personnel and financial management, and technical standards and so on, which are difficult for current professionals to master. From this, we can see how important it is to cultivate high-quality comprehensive professional management talents.

\section{CONCLUSION}

The solution to the financing problems of large stadiums is an inevitable requirement to meet the growing demand of the people for sports. The quasi-public product attributes of large stadiums, the traditional investment and financing system, and the imperfect investment and financing return mechanism are the main factors that cause the current dilemma of financing. We should actively change the role of the government, deepen the reform of the investment and financing system of large-scale sports stadiums, select a reasonable financing mode and cultivate high-quality comprehensive professional management talents, which will be conducive to the effective supply of large-scale sports stadiums.

\section{REFERENCES}

[1] Chen Yuanxin, Li Su. The Status Quo of Investment and Financing of Stadium Facilities in China's for Large-scale Sports Events and Its Marketization Reform[J].Journal of Shanghai Physical Education Institute, 2009,33(4):12-15.

[2] Li Shujuan, Li Jiangwei. A Summary of Investment and Financing of China's Sports Industry[J].Hubei Sports Science and Technology, 2017, 36(12): 1058-1060.

[3] Zeng Ming. Comparative Study on Investment and Financing Modes of Public Sports Stadiums in China $[\mathrm{J}]$. Finance and Accounting Research, 2012, (8): 75-77.

[4] Chen Yuanxin et al. Historical Review of the Supply of Sports Stadiums in China since the Founding of New China[J]. Journal of Xi'an Institute of Physical Education, 2009, 30(4): 411-418.

[5] Wang Jian, Chen Yuanxin. Study on Diversification of Investment and Financing Methods in Sports Stadiums in China [Z]. Compilation of the results of the fifth national sports stadiums census data research project, 2006: 4.

[6] Xiao Shuhong, Fu Qun, Lei Li. Study on Classification and Characteristics of Financing Modes of Large Sports Stadiums[J].Journal of Beijing Sport University, 2012,35(6):14-18.

[7] Xiao Shuhong, Fu Qun. Analysis of the Financing Mode of LargeScale Sports Stadiums in China and Its Development Trend[J]. Journal of Xi'an Institute of Physical Education, 2012,29(5):513-516. 